\title{
TEACHING THE SCOPE AND LIMITS OF GENERALIZABILITY IN QUALITATIVE RESEARCH
}

\author{
Ganesh N. Prabhu
}

Indian Institute of Management Bangalore, India. gprabhu@iimb.ac.in

\begin{abstract}
Generalizability is a concern in qualitative research as qualitative research may not offer sufficient data for statistical generalization. Analytical generalization is possible with richer qualitative evidence. I show that a case-based discussion can enable doctoral students to understand the scope and limits of analytical generalizability of qualitative research beyond the context studied. The case was an ethnography of the socialization of U.S. medical school students, where the author uncovered three insights about their life and priorities. Doctoral students were tasked to analytically generalize these insights beyond the medical student group studied. Students succeeded in generalizing insights to other medical students in that U.S. medical school, other medical schools in the U.S. and medical students in other countries with similar medical education. They faced logical limits in generalizing to practicing doctors, other life-saving professions, and nonmedical students. This classroom exercise helped doctoral students build understanding and confidence in generalizing qualitative research.
\end{abstract}

Keywords. Teaching, Generalization, Limitations, Scope, Application.

\section{INTRODUCTION - GENERALIZABILITY IN QUALITATIVE RESEARCH}

Generalization in research is an act of reasoning that involves making broader inferences from limited observations (Polit \& Beck, 2010). While generalization is considered essential to make new knowledge claims through research, the scope and limits of generalization may differ based on both methods and observations. Three ways in which generalization can be made from limited data studied by a researcher are: (a) sample to population extrapolation; (b) analytic generalization; and (c) case-to-case transfer (Firestone, 1993). Of these three ways, sample to population generalization is not possible in qualitative research as the number of cases studied is usually too small to allow it.

Claims to generalization in qualitative research are therefore typically made on grounds of case to case transfer (Firestone, 1993). The cases studied by the qualitative researcher and the potential cases to transfer are often limited. These limitations lead to a major criticism of qualitative research - the limited scope of generalizability of research results. Qualitative researchers are often tentative in claiming generalizability. They often underclaim the generalizability of significant results by limiting their generalization only to what is possible by using a case to case transfer logic. Unwillingness to generalize beyond the immediate study and the possible criticism of the generalizations made, if any, using only case to case 
transfer logic, makes qualitative research seem limited in scope. Typically, research proposals for limited scope studies that are not amenable to generalization beyond the limited set of cases studied are usually more difficult to justify. Moreover, qualitative research themes are often seen as driven by a researcher's interest than by their intrinsic salience in building new theory or in theory bridging to build new insights that are of theoretical and practical relevance (Burgelman, 2020). Qualitative research is missing the wider scope of applicability proposed by large sample quantitative researchers in qualitative research, which emphasizes either the intrinsic importance of the cases studied or offers limited possibilities of case to case transfer (Guenther \& Falk, 2019).

In this paper, I take forward the view that carefully constructed analytic generalizations that are based on rich qualitative data from qualitative research can significantly improve the quality and scope of generalization in qualitative research (Firestone, 1993). However, qualitative researchers need to be trained at an early stage to better understand the use and process of doing analytical generalization from their qualitative research. I demonstrate how the process of analytical generalization can be effectively taught to early stage researchers through an in-class exercise based on a single case study (Kennedy, 1979), thus encouraging students to attempt qualitative research with greater impact.

\section{A DESCRIPTION OF THE CASE}

It is important that qualitative researchers are trained early to examine the scope and limits of the generalizability of their qualitative research efforts. This paper describes an in-class, guided, rich case discussion that I used to build a practical understanding of generalizability in the first session of a first-year doctoral course on qualitative research at the Indian Institute of Management (IIM), Bangalore. I also used the case in an "Introduction to Research" session for doctoral students in another IIM.

The in-class session required prior reading of an ethnographic journal article (Becker, 1993) that is derived from a book widely considered as a classic in ethnographic studies (Becker et.al., 1976). The short article gives an ethnographic account of the in-situ study of the intense socialization process of under-graduate students in a medical school in the United States. Since doctoral students of management in India rarely enter the doctoral program with any undergraduate education in medicine, the students in this course, over the years, were usually only from non-medical streams. The doctoral students in the course were therefore unlikely to have any preconceived views on the socialization process of medical 
students based on their own experiences as described in the article. This made the article an ideal discussion case. Students in the doctoral program were broadly aware that graduate level medical coursework is difficult due to a relatively vast syllabus compared to the graduate subjects that they had themselves undertaken, with difficult examinations based on voluminous textbooks that were difficult to read. Graduate study in medicine also involved practical medical examinations and supervised medical assessment of new patients that the medical student had never seen before.

The article describes how the ethnographer, who is a social science student, seized the opportunity to accompany and observe medical students when they went on their rounds to examine patients in the medical school hospital. As a participant observer, the ethnographer was also privy to the private comments made within the student group about the patients that they saw and their ailments. As medical students tend to use medical words and acronyms while discussing patients, the ethnographer got into the practice of clarifying with some students about each new word that he heard in the discussions among the medical students. This practice helped the ethnographer to better understand the conversations that were happening around him. He was, however, puzzled when the medical students were not able to clearly define the term 'crock' as used in reference to some patients.

\section{GENERALIZING FROM THE CASE CONTEXT}

The ethnographer came across a term 'crock' as used by medical school students to dismissively label a patient who gave a long-winded description of her many symptoms that had no physical manifestation. He first spent considerable time with the students to develop a consistent description of what specifically made a patient a crock. He was puzzled about why medical students were dismissive of crocks, as such patients may be potentially lucrative to have as a practicing doctor. He speculated on their underlying reasons to dislike crocks and tested his speculations. He dismissed some speculations based on inherent contradictions. Over time, his conversations with medical students led him to identify three underlying reasons why medical students viewed crocks negatively. These three reasons provided the ethnographer insights into the professional priorities of medical students.

The first reason crocks were viewed negatively was that crocks took up too much of the medical student's time in describing their many symptoms that had no physical manifestation. Once the medical students knew how to identify a crock, they would rather have used their time productively elsewhere to learn about other medical conditions. The 
only way to treat a crock was to listen quite patiently, but really do nothing medically. He generalized this to state that time was critical for medical students and crocks only wasted their time.

The second reason was that crocks did not have any serious ailments that required medical expertise that was lifesaving. The ethnographer connected this reason with the fact that doctors who specialized in ailments that could cause death if untreated were more highly regarded within the medical profession than doctors who specialized in ailments that do not cause death if untreated. So, medical students wished to spend more time on patients with ailments that could potentially kill them, rather than on crocks. He generalized this to state that medical responsibility was critical for medical students. Treating crocks by listening to them did not help students in their medical responsibility to save the lives of the sick.

The third reason was that crocks did not offer medical students any valuable clinical experience that they eagerly sought in their time in medical school. Medical students sought clinical experience that was not found in books or journals. The time spend with crocks did not add to their clinical experience. He generalized this to state that clinical experience was critical for medical students. Treating crocks by listening to them was not helping them add to their clinical experience required to save lives of the sick.

These three generalizations should be viewed in the medical student's context where clearing year to year examination-based hurdles was typically very difficult. While written examinations required absorbing knowledge from voluminous textbooks, practical examinations involved diagnosis of patients with ailments that the student may not have yet read about nor seen in their hospital rounds until then. Examining professors did not consider the inability to diagnose patients with previously unseen ailments by the student as a matter of excusable bad luck and would fail them. Stories of such 'bad luck' failures to clear practical examination hurdles were thus a common nightmare among medical students. Consequently, medical students were typically not syllabus bound in their study. They were keen to absorb as much practical knowledge as they can. This led them to trade allotted patients among themselves to maximize their learning by examining a variety of patients as they learned beyond their medical books. Their doctor professors emphasized the importance of clinical experience as it reduced the incidence of incorrect diagnoses of patients by both students and practicing doctors, which impacted collective reputation. 


\section{GENERALIZING BEYOND THE CASE CONTEXT}

Once these three reasons and their associated generalizations by the ethnographer were discussed and understood by the doctoral students, they were asked to examine if these three reasons and their associated generalizations (which were all deemed to be logically sound) were possible to generalize beyond the specific medical school cohort that was studied by the ethnographer. In the first stage of the exercise, the doctoral students agreed that purely by the logic presented, the same or very similar behavior was likely to be found in all the other student cohorts in that specific medical school as they would all be studying with the same medical pedagogy and the same medical examination system. Additionally, the teaching and examining faculty were likely to be the same across the student cohorts.

In the second stage, I pushed the doctoral students to extend the same logic further. They agreed that the same behavior was likely to be found in other medical schools operating under the U.S. medical studies board. This extension of the logic was made with the knowledge that the teaching and examining faculty were different across medical schools in the U.S. Since they operate under one medical studies board, medical schools are likely to have similar methods of teaching and similar examination standards, thereby placing medical students under very similar pressures as found in the student cohort studied.

In the third stage, I asked the doctoral students to consider the generalization to medical schools outside the U.S. Students supported the view that the ethnographer's three reasons medical students disliked crocks, namely prioritizing the usage of time, the search for clinical experience, and the positive view towards doctors who save lives, were likely to exist among medical students outside the U.S. So, it was possible to generalize to medical schools worldwide. This generalization rested on the debatable premise that while specific standards of medical education may differ across countries, the methods of teaching and examination of medical students could not be very different. Those who graduate must be competent enough to be employed as doctors. Thus, there was likely to be enough self-driven effort by medical students to become competent doctors to save lives.

In the fourth stage, I asked the doctoral students to consider the generalizability of the ethnographer's three reasons to practicing doctors rather than just medical students. Here, doctoral students doubted the applicability of all the three reasons specifically among those doctors who may have been interested in earning well through their practice. They speculated that such doctors may like crocks as crocks offer recurring income even though 
they may waste their practicing time that could be better used to examine patients that could be cured. However, some doctors who are less interested in an earnings stream from crocks may direct crocks to other doctors rather than waste their professional time on them. Such doctors may thus behave more like medical students. The class then discussed examples of doctors they may know of the latter type. This provided a way to directly experience the limits of generalizability to all doctors.

In the fifth stage, I asked doctoral students to consider generalization to students in other types of professional programs. Students typically suggested programs that train students to deal with "life and death" issues, such as aircraft pilot training. Other students then questioned this premise on the grounds that while such professionals do deal with "life and death" situations, it is not the core objective of their training, while doctors are trained to save lives. Another issue raised was that while pilot training is rigorous and flying experience is important, pilots can die when they make a mistake while flying. This discussion provided a way to directly experience the limits of generalizability to other professions.

In the sixth stage, doctoral students identified other professions that save lives and involve clinical experience such as criminal lawyers. Students speculated that while similar learning behaviors may exist among law students, criminal lawyers who save lives may not be differentially valued over civil lawyers who have no such direct role in saving lives. This premise could be cross-checked in class if there was a law student or if any student had parents who were lawyers. Another difference is that while criminal lawyers can argue a case well and thus save an accused, it is the judge and jury that make the final call, while a doctor's mistake may be directly responsible for a patient's death. This again tested the limit of generalizations being made to other professions from the case of medical students.

\section{CONCLUSIONS}

This 90-minute discussion exercise with doctoral students on first generalizing from the case context and then generalizing beyond the case context effectively introduced students to the concept of analytical generalization. The discussion showed the power of analytical generalization based on application of a discovered underlying logic beyond the context of the single case over sampling generalization based on the statistical incidence in a sample being extrapolated to its population. It was interesting that the underlying logic of the analytical generalization changes in each of the six stages. 
Through this exercise, doctoral students were encouraged to seek ways to achieve analytical generalization in their qualitative research and present it effectively to draw attention to their new knowledge claims (Englander, 2019). They were encouraged to design research that planned for anticipated generalizations (Payne \& Williams, 2005) that were valid (Hayashi et al., 2019). Doctoral students realized through the exercise that qualitative research findings are amenable to logic based generalization and such generalizations can be valid even without large enough samples to do statistical generalization. They realized that it was possible to generalize their qualitative research output beyond the limited potential offered by case to case transfer based generalization.

The feedback from students on this guided exercise has been very positive over the several years that this exercise has been used. It has also helped that the case is memorable and adds richness to the classroom discussions. I use the "crock case," as doctoral students tend to call it, to explain and understand new concepts in qualitative research that the students cover in the nineteen sessions that follow this discussion.

\section{REFERENCES}

Becker, H. S. (1993). How I learned what a crock was. Journal of Contemporary Ethnography, 22(2), 28-35. https://doi.org/10.1177/089124193022001003

Becker, H. S., Geer, B., Hughes, E. C. \& Strass, A. L. (1976). Boys in white: Student culture in medical school. Transaction Publishers.

Burgelman, R. A. (2020). Bridging history and reductionism: A key role for longitudinal qualitative research. In L. Eden, B. Nielsen, \& A. Verbeke (Eds.), Research methods in international business (pp. 235-258). Palgrave Macmillan.

Englander, M. (2019). General knowledge claims in qualitative research. The Humanistic Psychologist, 47(1), 114. https://doi.org/10.1037/hum0000107

Firestone, W. A. (1993). Alternative arguments for generalizing from data as applied to qualitative research. Educational Researcher, 22(4), 16-23. https://doi.org/10.2307/1177100

Guenther, J. \& Falk, I. (2019). Generalizing from qualitative research: A new old approach. Qualitative Report, 25(5), 1012-1033. https://nsuworks.nova.edu/tqr/vol24/iss5/6/

Hayashi, P., Abib, G. \& Hoppen, N. (2019). Validity in qualitative research: A processual approach. Qualitative Report, 24(1), 98-112. https://nsuworks.nova.edu/cgi/viewcontent.cgi?article=3443\&context=tqr

Kennedy, M. M. (1979). Generalizing from single case studies. Evaluation Quarterly, 3(4), 661-678. https://doi.org/10.1177/0193841X7900300409

Payne, G. \& Williams, M (2005). Generalization in qualitative research. Sociology, 39(2), $295-314$. https://doi.org/10.1177/0038038505050540

Polit, D. F. \& Beck, C. T. (2010). Generalization in quantitative and qualitative research: Myths and strategies. International Journal of Nursing Studies, 47(11), 1451-1458. https://doi.org/10.1016/j.ijnurstu.2010.06.004 